\title{
Media, geschiedenis en representatie
}

\author{
Frank van Vree
}

Toegegeven, de term 'representatie' heeft iets ongrijpbaars, iets hinderlijk raadselachtigs. In sommige teksten struikel je er letterlijk over. In andere - veelal empirische - studies die zich bij uitstek richten op een analyse van voorstellingen en hun betekenis, context en ontstaansgeschiedenis, komt het woord 'representatie' zelfs niet voor. Sommige onderzoekers en theoretici hanteren de term als een passe-partout of, in minder vleiende bewoordingen, als een soort bezweringsformule. Anderen zien de opvatting dat het sociale en culturele leven kan worden geanalyseerd in termen van representatie, vooral als een poging om mist te zaaien en de wetenschappelijke blik - al dan niet met politieke bedoelingen - te vertroebelen.

De polarisatie rond het begrip 'representatie' kan worden herleid tot verschillende oorzaken. Een aantal daarvan heeft op het eerste gezicht weinig van doen met de analytische en wetenschappelijke waarde van het begrip. Achter het academische debat gaat niet zelden een strijd schuil tussen al dan niet gevestigde belangen, terwijl in andere gevallen diepgewortelde anti-theoretische sentimenten een rol lijken te spelen. Aan de andere kant dringt er soms iets door van angst om de boot te missen; vaker nog manifesteert zich de behoefte mee te willen surfen op de golven van een nieuwe wetenschappelijke mode.

De term 'representatie' wortelt in de filosofie en de esthetica, met vertakkingen in het recht, de politieke theorie, het theater en de beeldende kunst. Hij heeft een oude en veelzijdige stamboom, maar pas de laatste decennia een ruime verspreiding gevonden. In de meest weidse zin kan 'representatie' worden gedefinieerd als een voorstelling beladen met betekenis. Deze omschrijving sluit zowel beelden, teksten en voorwerpen als rituelen, gebaren en andere tekens in, waarmee het begrip als vanzelf een bemiddelende plaats toevalt in de studie van de cultuur. Dat laatste, 'cultuur', moet hier niet begrepen worden in de klassieke humanistische zin als de som van de meer verfijnde uitingen van de menselijke geest, maar als een proces van interpretatie en zingeving, 'de productie en uitwisseling van betekenissen'.' Foto's, gesprekken, medische rapporten, standbeelden, muziekopnamen en wetenschappelijke verslagen verwijzen immers niet alleen - 
naar iets buiten de voorstelling zelf, een afwezige persoon, een voorwerp, een begrip, een handeling - maar ze doen dat ook op een specifieke manier. Evenals schilderijen, verhalen, gebouwen, televisieprogramma's en filmbeelden zijn deze voorstellingen gekneed en gevormd naar de tradities van het vak en gemaakt met behulp van bepaalde materialen en technieken; ze bevatten stijlfiguren en andere al dan niet expliciete codes, die bovendien door elkaar opvolgende generaties en uiteenlopende sociale groepen verschillend beoordeeld en begrepen kunnen worden. ${ }^{2}$

Voor het antwoord op de vraag waarom juist deze benadering de laatste decennia zo aan kracht heeft gewonnen, wijs ik op twee nauw met elkaar verweven ontwikkelingen. Ten eerste het besef dat ook wetenschappelijke kennis bestaat uit geconstrueerde voorstellingen. Ten tweede de ervaring dat de studie van de cultuur in brede zin zich niet of nauwelijks laat vatten in termen van een positivistisch georiënteerde wetenschap. De omslag die zich als gevolg hiervan in de sociale wetenschappen en humaniora heeft voltrokken, wordt doorgaans angeduid als de linguistic of discursive turn.

Wat de studie van de media betreft, heeft de linguistic turn niet over de hele linie tot een verschuiving in benadering en oriëntatie geleid. Enkele takken van onderzoek, zoals de studie van de institutionele en technische aspecten van de media of het 'klinische' publieksonderzoek, zijn tot nu toe vrijwel immuun gebleken voor deze omslag. In sommige gevallen ontbrak de noodzaak zich te heroriënteren. Op het terrein van de film bijvoorbeeld, had het onderzoek naar betekenissen al veel eerder zijn intrede gedaan, en wel in de vorm van de semiotiek, die haar wortels overigens ook vond in de taalwetenschap.

Op een aantal andere gebieden heeft de herdefiniëring van het communicatieproces in termen van representatie en betekenistoekenning echter ingrijpende gevolgen gehad. Dat geldt uiteraard in de eerste plaats voor het inhoudsonderzoek en de studie van de audiovisuele media, vooral de televisie, die door de linguistic turn sterk tot ontwikkeling is gekomen. Maar ook op de traditioneel 'harde' deelgebieden van de communicatiewetenschap is de invloed ervan aanwijsbaar, zoals kan worden afgeleid uit de omschrijving van het begrip 'nieuws' door een van de meest vooraanstaande wetenschapsbeoefenaren op dit gebied, Michael Schudson, verbonden aan de Universiteit van Californië in San Diego. Nieuws, zo stelt hij, is een vorm van cultuur, van betekenistoekenning. Verslaggevers, redacteuren en andere makers van nieuws 'operate, often unwittingly, within a cultural system, a reservoir of stored cultural meanings and patterns of discourse', waarbij zij zich verder laten leiden door bepaalde conventies over hun bronnen en onuitgesproken verwachtingen over het publiek. $^{3}$ 
Een dergelijke opvatting van communicatie - als een proces van bewuste en onbewuste betekenisgeving - staat op gespannen voet met het sociaal-wetenschappelijke paradigma van de 'traditionele' communicatiewetenschap, dat in essentie terug te voeren is op het lineaire model zenderboodschap-ontvanger en de gedachte dat de inhoud van de media - teksten, beelden, geluiden - te bestuderen zijn als natuurlijke objecten. Van een paradigmatische revolutie is evenwel geen sprake. De vooronderstellingen van de sociaal-wetenschappelijke benadering, vervat in de klassieke statements van founding fathers als Berelson en Lasswell, zijn in de loop der jaren genuanceerd, bijgesteld en aangevuld, en zijn dan ook in alle opzichten nog levensvatbaar. Bovendien heeft zich op een aantal onderzoeksterreinen al eerder een verschuiving in de richting van op taal en betekenis georiënteerde methoden voorgedaan.

Zo bezien lijken de sociaal-wetenschappelijke en de cultuur-wetenschappelijke benadering elkaar aan te kunnen vullen. Opvallend is in ieder geval dat de tweede, op representatie gerichte benadering, waarin semiotiek en discours-analyse een centrale plaats innemen, vooral vruchtbaar is gebleken op terreinen waar de positivistisch georiënteerde communicatiewetenschap, die na de Tweede Wereldoorlog het vakgebied beheerste, het vrijwel geheel liet afweten. Daarbij kan men denken aan de analyse - in een bredere sociaal-culturele context - van de latente inhoud van de media, of het onderzoek naar de historische en culturele dimensies van het communicatieproces. Vooral het onderzoek op het vlak van de visuele en audiovisuele media, zoals de fotografie, film en televisie, en de studie van de populaire cultuur zijn door de 'culturalistic approach' tot bloei gekomen.

'Representatie' als analytisch concept kan buitengewoon vruchtbaar zijn voor de beoefening van mediageschiedenis. Films, foto's, televisieprogramma's, muzieknummers, tijdschriften en nieuwsberichten kunnen stuk voor stuk worden geanalyseerd als voorstellingen, beladen met betekenis. Concrete beelden, teksten en geluiden kunnen worden 'gelezen' door ze te relateren aan de heersende conventies en tradities van het genre, aan de eigenschappen van het medium, de maatschappelijke context en voorstellingen in andere media of de literatuur, religie, kunsten, wetenschap.

Welke opvattingen van trouw of mannelijkheid kunnen uit deze tijdschriften worden gedistilleerd? Welke notie van politiek wordt in deze programma's geconstrueerd? Welk beeld van Afrika wordt in deze kranten gevormd? Hoe heeft het werk van deze fotografen bijgedragen aan de constructie van een nieuwe nationale identiteit? ${ }^{2}$ Door dergelijke vragen te stellen dringt men langzaam maar zeker door tot de kern van het proces waar het bij de media om gaat: de uitwisseling van opvattingen, gevoelens, ideeën, kennis. Precies dat onderscheidt media van zeepfabrieken, jour- 
nalisten van krullenjongens en regisseurs van kapiteins - en mediagebruik van de consumptie van zeep, hout en haringen.

Dit alles is uiteraard niet bedoeld als een desavouering van het onderzoek naar de geschiedenis van de productie, financiering en distributie, de ontwikkeling van de techniek en de infrastructuur, het leven van individuele fotografen, schrijvers en acteurs, de politieke bemoeienissen en juridische kaders. Zonder deze studies kan de interpretatie van de voorstellingen immers niet worden verankerd in hun historische context en is de mediahistoricus gedoemd tot 'presentistische', min of meer arbitraire speculaties over de betekenis. Aan de andere kant is het van het grootste belang ook in het specialistische onderzoek zich permanent bewust te zijn van de zuiver communicatieve dimensies van de media.

Door zich te concentreren op de inhoud van de media, op de concrete voorstellingen, schuift de mediageschiedenis als vanzelf op naar het terrein van de cultuurgeschiedenis. Daar hoort zij ook thuis. In het bijzonder de geschiedenis van de negentiende en twintigste eeuw, waarin de 'massa' zich op alle maatschappelijke terreinen deed gelden, is zonder een diepgaande bestudering van de inhoud van de pers, film, radio, fotografie en televisie onbegrijpelijk. Juist de media moeten beschouwd worden als de kristallisatiekernen van de moderne massacultuur. En het moet worden gezegd: op dit moment is er in Nederland nog maar nauwelijks iets gedaan op het vlak van de studie van de representatie in de moderne media.

\section{Noten}

I S. Hall (red.), Representation. Cultural representations and signifying practices, Londen 1997.

2 Zie ook: Feit \& fictie. Tijdschrift voor de geschiedenis van de representatie, vol. I nr. I, 1993, p. 6-8.

3 M. Schudson, The power of the news, Harvard 1995.

4 Een aantal van dit soort vragen wordt op exemplarische wijze uitgewerkt in Representation, een onlangs verschenen methodische introductie in de serie 'Culture, Media and Identities'. Dit boek (zie noot I), waarvan een van de architecten van de Britse cultural studies, Stuart Hall, de redactie voerde, is in de keuze van thema's misschien wat modieus, maar maakt wel precies duidelijk waar het om gaat. 